\title{
Review Article. Interactions of Determinants in the Ontogeny of the Gastrointestinal Tract: a Unified Concept
}

\author{
EMANUEL LEBENTHAL ${ }^{(97)}$ AND P. C. LEE \\ Division of Gastroenterology and Nutrition, Children's Hospital of Buffalo, Departments of Pediatrics and \\ Biochemistry, State University of New York at Buffalo, Buffalo, New York, USA.
}

The development of the gastrointestinal tract previously was the subject of the anatomist and embryologist who restricted their study to gross morphology and histology. As the discipline of developmental biology advanced, the physiologic and biochemical aspects of gastrointestinal ontogeny became of equal or greater importance. In this review we correlate the results of studies in utero and postnatal development in animal models into a coherent description. We intend to provide a unified concept for further exploration in the field of developmental gastroenterology.

Concept of gastrointestinal (GI) development. The development of the GI tract, like that of other organs, results from the interaction of four major determinants: genetic endowment, an intrinsic developmental and biological clock, endogenous regulatory mechanisms, and environmental influences (Fig. 1). To illustrate the interaction of determinants, we will restrict the discussion to the exocrine pancreas and small intestinal mucosa.

Genetic endowment. The genetic endowment is contained in the base sequence of the DNA molecules and controls the differentiation of specific tissues and cells. This has been shown in an animal model in which isolated rat fetal pancreas continued to develop to the adult cell type when cultured in vitro $(21,67)$. In pancreatic explants, the temporal appearance of zymogen granules and the increase of alpha amylase, lipase, and chymotrypsin contents closely resembles that of intrauterine development. Similarly, segments of small intestine from fetal rats developed normally after implantation in the kidney $(16,32)$, the subcutaneous space (46), or when cultured in vitro (11). The changes in mucosal disaccharidases in a similar system paralleled those found in in situ development $(16,32)$.

Genetic endowment varies from one generation to another, via mutation, which occasionally results in an inborn error of metabolism. Hereditary diseases of the exocrine pancreas such as cystic fibrosis and selected rare deficiencies of lipase (17), trypsinogen $(64,88)$, and amylase $(55)$, are examples of the results of mutation. In the small intestine, some disaccharidase deficiencies have been demonstrated to be inherited as Mendelian traits (33). These genetic disorders provide researchers with natural experiments in which the molecular mechanisms involved in digestive processes can be studied. For example, congenital pancreatic lipase deficiency has been shown to be a lack of synthesis of the enzyme moiety (17). In congenital sucrase-isomaltase deficiency, sucraseisomaltase complex in the brush border of mature epithelial cells of the small intestine is greatly reduced $(10)$ or absent $(2,19)$ in affected children. An abnormal protein is found in the cytoplasm of these enterocytes and has been interpreted to be a modified sucrase-isomaltase complex, which is not transported to the brush border (77). Other disease entities, such as glucose-galactose malabsorption, have been shown to be due to the lack of a membrane carrier protein $(12,62)$, and can serve as models for studying the active transport of glucose and galactose.

Changes in genetic endowment are sometimes the consequence of evolutionary selection. Persistent lactase activity segregates as an autosomal dominant trait whereas adult hypolactasia is recessive $(70,75)$. The difference in gene frequency found in several ethnic groups has been related to previous differences in ruminant milk consumption. Among Orientals, milk is consumed only in the nursing period, whereas Northern Europeans have often consumed significant amounts of milk throughout life. The similarity in chromatographic properties, substrate affinities, $\mathrm{pH}$ optimum and electrophoretic mobility of the neutral lactases from infants and adults with or without hypolactasia (54) does not support the concept of a structural gene mutation as the basis for the persistence of high lactase activity in adults. Experimentally, a delay in the postweaning decline in lactase activity has been observed in rat pups subjected to prolonged nursing (52).

Biologic clock. The biologic clock can be defined as a predetermined temporal sequence of events in ontogeny, that is genetically controlled and species specific. For example, the developmental sequence of pancreatic enzymes in humans is in sharp contrast to that found in rats. In rats, all pancreatic enzymes appear within several days at the beginning of the last fetal period $(31,74)$. Our experience with pancreatic tissues from human fetuses shows that by 17 wk of gestation, trypsinogen can be demonstrated but lipase cannot be detected until $34 \mathrm{wk}$ of gestation. Amylase is essentially absent in the fetal pancreas, but is present at very low concentrations in the newborn period. The differences between human and rat in pancreatic development should serve to caution those who extrapolate from animal findings to the human.

In general, the pattern of development follows a fairly well established sequence beginning with the differentiation of the primordia into endo-, meso-, and ectoderm. Through the interactions of these three germ layers, patterns of differentiation emerge. The anatomic specialization of various segments of the gastrointestinal tract follows a species specific sequence with some individual variability. In human development, the anatomic differentiation of the fetal gut has progressed by $20 \mathrm{wk}$ of gestation to the extent that it resembles that of the newborn. Secretory and absorptive functions develop at a different rate; the intestinal absorptive process is partially available before $26 \mathrm{wk}$ of gestation, whereas pancreatic secretion cannot be stimulated even in the newborn period.

The temporal sequence of gene expression during development is illustrated by the changing profiles of intracellular and secretory proteins. The proteins synthesized by the embryonic rat pancreas at various times of gestation have been analyzed by two dimensional polyacrylamide gel electrophoresis. From 14-18 days of gestation, the profile of proteins synthesized by the embryonic pancreas is fairly constant and similar to those of the intestine, lung, and other tissues derived from mesenchyme at the same stage of development (93). By day 18 of gestation, the synthesis of the majority of these embryonic proteins begins to decrease, and the synthesis of zymogen predominates. Amylase and chymotrypsinogen are detected between 15-18 days of gestation, but trypsinogen, ribonuclease, elastase, and lipase are not detectable before 


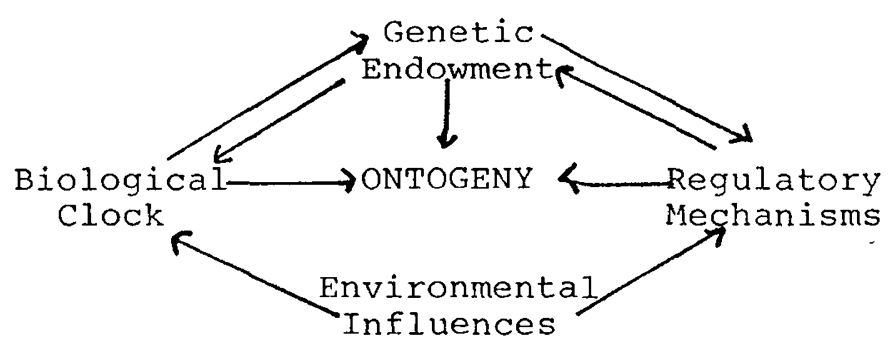

Fig. 1. Interaction of determinants in the ontogeny of the gut.

day 18 of gestation. Associated with the appearance of zymogens, the apparent rate of RNA synthesis increases 7.5-fold from day 15 to day 19 (8). The increase in zymogen content lags behind that of RNA synthesis with peak RNA synthesis reached at day 18 , and that of zymogen synthesis at day 19. This suggests that the progression of important biomolecules are precisely controlled and appear at preprogrammed times during ontogeny.

The development of specific organs of the digestive tract in utero occurs at different rates (Table 1), and involves both morphogenesis and cytodifferentiation. In the pancreas, morphogenesis involves the interaction between meso- and endoderm, increase in cell number and size, and molding of cells to produce the familiar glandular structure of acinar cells, centroacinar cells and intercalated tubules. Cytodifferentiation involves the acquisition of the ability to synthesize secretory proteins and the cytoplasmic structures required for their transport and secretion.

Because both morphogenesis and cytodifferentiation depend on underlying gene activity and normally are congruent, it is important to know whether the gene sets involved in morphogenesis and cytodifferentiation are subjected to obligatory coregulation or if they are independently regulated.

Pancreatic acinar cells show two distinct intrauterine developmental periods in rats (74). The embryonic endoderm (predifferentiated) matures to a protodifferentiated state with a low level of exocrine enzymes from the 11 th to the 15 th day of gestation. A second transition occurs from the 15th day of gestation until birth, when protodifferentiated cells have a rapid increase in rough endoplasmic reticulum coupled with the appearance and accumulation of exocrine enzymes. Spooner et al. (82) studied the degree of obligatory coupling between cytodifferentiation and morphogenesis in the development of the mouse pancreas. They isolated protodifferentiated pancreatic epithelia from investing mesoderm and cultured the tissue on a plastic substratum. Within $24 \mathrm{~h}$, the epithelium had spread to form a monolayer. Under these conditions, no identifiable acini were formed and the cells did not undergo mitosis. Such an observation is consistent with the absence of mesenchymal cells or mesenchymal factor in these cultures. In spite of the absence of morphogenesis, cytodifferentiation progresses on schedule. Thus, over a period of 5-7 days amylase specific activity rose 100-fold and zymogen granules appeared in the cells. This change observed in the mouse is similar to those reported by Rutter et al. (74) in the rat pancreas in situ. These results suggest an apparent dissociation between the regulation of cytodifferentiation and the regulation of morphogenesis in the mouse pancreatic acinar tissue during the second transitional period in fetal development.

The mechanism of cytodifferentiation itself is not well understood. So far no satisfactory answer has been formulated. One hypothesis assumes that in early development the commitment to the expression of different fractions of the genome is controlled by the intracellular environment or by the position of the cell relative to surrounding cells. It is conceivable that each cell or group of cells has a binary kind of decision, i.e., to activate or not to activate the function of a specific gene or set of genes. It has been estimated that the number of binary decisions necessary for transformation into a pancreatic acinar cell, beginning with the morula stage, could be as few as 10 or 12 .

It has been suggested that molecules at the cell surface are critical in modulating the decisions that cells must make if differ- entiation is to proceed. Changes in the cell surface during various stages of development have been studied and recorded. It is not known whether morphogenesis and differentiation lead to a change in membrane properties, or if the change in membrane properties results in morphogenesis and differentiation. Studies of the pancreas showed that acinar cells strongly bind all lectins; on the other hand, endocrine and centroacinar cells selectively bind only certain specific lectins (60). The characteristics of these lectin receptors have been found to change during development of the rat pancreatic acinar cells (61). Similar studies of small intestinal epithelial cells during postnatal development of the rat have also shown interesting results (13). Rats younger than $3 \mathrm{wk}$ of age do not have a cell surface change as detected by differential binding of lectins during the migration of cells from the crypt to villus compartment, as occurs in the adult intestine. These lectin binding experiments perhaps can be modified and extended to investigate the effect of membrane modification through lectin binding on differentiation. In this way it may provide insight into the change in membrane properties as the cause or result of morphogenesis and differentiation.

Regulatory mechanisms. The expression of the genetic endowment at various stages in gastrointestinal development is modified by regulatory mechanisms that have been studied extensively in animals. Hormonal control plays a major role in the ontogeny of the small intestine $(41,63)$. Adrenalectomy, hypophysectomy, or thyroidectomy delays the development of the gut. Administration of glucocorticoids or thyroxine to suckling mice and rats, before a critical stage in maturation, causes elongation of the microvilili, a concomitant increase in the activities of brush border, membrane-bound enzymes, sucrase (29), alkaline phosphatase (73),

Table 1. Temporal sequence of development of the gastrointestinal tract in human fetus

\begin{tabular}{|c|c|}
\hline Anatomic development & \\
\hline & \\
\hline superficial glands develop & $20 \mathrm{wk}$ \\
\hline squamous cells appear & $28 \mathrm{wk}$ \\
\hline Stomach & \\
\hline gastric glands form & $14 \mathrm{wk}$ \\
\hline pylorus and fundus defined & $14 \mathrm{wk}$ \\
\hline Pancreas & \\
\hline differentiation of endo and exocrine tissue & $14 \mathrm{wk}$ \\
\hline Liver & \\
\hline lobules form & $11 \mathrm{wk}$ \\
\hline Small intestine & \\
\hline crypt-villi develop & $14 \mathrm{wk}$ \\
\hline lymph nodes appear & $14 \mathrm{wk}$ \\
\hline Colon & \\
\hline diameter increases & $20 \mathrm{wk}$ \\
\hline villi disappear & $20 \mathrm{wk}$ \\
\hline Functional development & \\
\hline Sucking and swallowing & \\
\hline only mouthing & 28 wk \\
\hline immature suck-swallow & $33-36$ wk \\
\hline Stomach & \\
\hline gastric motility and secretion & $20 \mathrm{wk}$ \\
\hline Pancreas & \\
\hline zymogen granules & $20 \mathrm{wk}$ \\
\hline Liver & \\
\hline bile metabolism & $11 \mathrm{wk}$ \\
\hline bile secretion & $22 \mathrm{wk}$ \\
\hline Small intestine & \\
\hline active transport of amino acids & $14 \mathrm{wk}$ \\
\hline glucose transport & $18 \mathrm{wk}$ \\
\hline fatty acids absorption & $24 \mathrm{wk}$ \\
\hline Enzymes & \\
\hline$\alpha$-glucosidases & $10 \mathrm{wk}$ \\
\hline dipeptidases & $10 \mathrm{wk}$ \\
\hline lactase & $10 \mathrm{wk}$ \\
\hline enterokinase & $26 \mathrm{wk}$ \\
\hline
\end{tabular}


and enteropeptidase (47). Cortisone (10-50 mg/ $100 \mathrm{~g}$ body weight) and triiodothyronine $(20-50 \mathrm{mg} / 100 \mathrm{~g}$ body weight $)$ given to pregnant rats between 16-21 days of gestation are effective in promoting the early appearance of sucrase within the intestine (29). A lower dose of cortisone ( $5 \mathrm{mg} / 100 \mathrm{~g}$ body weight) and a shorter term of injection is not effective (47). In contrast, these same hormones have no effect on the small intestine of adult rats, independent of dose and duration of treatment.

Hormonal control of pancreatic development has been demonstrated. Glucocorticoid administered to embryonic rat pancreas in tissue culture does not lead to precocious appearance of exocrine enzyme but rather enhances the synthesis and accumulation of those enzymes that were previously present (69). In contrast, premature induction of alpha-amylase is seen in postnatal development of the rat pancreas with the injection of dexamethasone (76). Presumably, glucocorticoid serves as a postnatal enzyme inducer but acts as a prenatal enzyme modulator in the development of the rat exocrine pancreas.

More direct evidence for the role of corticosteroid in enzyme development is provided by a recent study of changing plasma levels of corticosterone. The concentration of serum corticosterone is less than $1 \mathrm{mg} / \mathrm{dl}$ from birth through day 12 and then increases to a peak level $(10 \mathrm{mg} / \mathrm{dl})$ at day $24(25)$. The increase in corticosterone precedes that of sucrase in the brush border of the small intestine and of alpha-amylase in the pancreas. Such a temporal sequence of events suggests a role of corticosteroid in producing developmental maturation by increasing enzyme concentrations in the gastrointestinal tract.

Other hormones that may be important in controlling gastrointestinal development include pancreozymin, gastrin, secretin, motilin, and enteroglucagon. Pancreozymin, gastrin, and enteroglucagon have trophic effects on the gastrointestinal tract $(18,28)$. Their levels have been shown to be significantly increased after birth $(56,57)$. Their effects on the development of the GI tract require further investigation.

The development of gastrointestinal secretory function, particularly in response to hormonal stimulation, is especially intriguing. Hormonal action depends on both the availability and activity of the hormone, and the responsiveness of the target cell. Hormone receptors are the elements of the target cell that specifically recognize and bind the hormone, and by so doing initiate the cellular response to hormone. The degree of response of the target cell is determined not only by the amount of effective hormone reaching it, but also by the number of receptors on its surface (86). Studies in rats showed that during development the maturation of cellular function is accompanied by an increase in the number of receptors.

Although neonates have secretin, pancreozymin and gastrin, their pancreatic acinar cells are not responsive to secretin and pancreozymin (48), nor is the gastric mucosa responsive to gastrin (15). These tissues are therefore not fully functional. The mechanism of response of the exocrine pancreas has not been investigated, but studies of the developing gastric mucosa; however, revealed interesting results.

Human newborns, as well as neonatal dogs and rats have high levels of gastrin in their sera, yet have low acid output. Exogenous gastrin is an ineffective stimulant despite the presence of seemingly "anatomically developed" parietal cells $(14,58,72,84)$. In these species neither endogenous nor exogenous gastrin has an effect on the target cell. Parietal cells of 15-day-old rats are capable of enhanced acid secretion in response to histamine, but are unresponsive to gastrin. In spite of high serum levels, their antral gastrin concentrations are low. In addition, their parietal cells are unresponsive to gastrin and do not bind the hormone. Gastrin stimulated acid secretion does not become significant until the rats are 20 days old. When serum gastrin levels decrease, antral gastrin levels increase, and gastrin receptors appear (84). The absence of gastrin response during the first $2 \mathrm{wk}$ of life in rats is therefore associated with a lack of gastrin receptors in the parietal cells of these rats.

In adult rats it has been shown that the number of gastrin receptors is regulated in part by the serum level of gastrin (85). The maintenance of these receptors seems to depend only in part on endogenous circulating gastrin, because the removal of nearly all circulating gastrin by fasting, antrectomy or feeding a liquid diet will decrease the number of gastrin receptors by $40 \%$ (85). If one accepts the role of circulating gastrin levels in the regulation of its own receptor, one can hypothesize the absence of a regulatory effect of gastrin in the newborn period. It is also evident that gastrin cannot induce the appearance of its own receptor in the rat parietal cells during the first 2 wk of life (84).

Unlike the response to gastrointestinal hormones, the difference in susceptibility of the intestine to glucocorticoid stimulation at various stages of development does not seem to be related to a limitation in the number of glucocorticoid receptors. Sufficient quantities of receptors have been found in the intestine of preand postnatal and adult rats (26). Thus, receptor availability is not the limiting factor in controlling the susceptibility of the intestine to glucocorticoid.

Recent studies in localization and characterization of gut and brain peptides have led to yet another concept of a diffuse neuroendocrine system that is believed to consist of a series of cells derived from the embryonic epiblast (94). These cells have been identified to be asymmetrically distributed throughout the central nervous system and bowel and may secrete as many as 35 different physiologically active peptide hormones. Therefore, in addition to hypophyseal-hypothalamic control of ontogeny, this neuroendocrine system may provide additional control of developmental processes.

Studies on the development of the gut have indicated that specialized cells from the fetus produce large amounts of 5 hydroxy-tryptamine $(5 \mathrm{HT})$ that were not detected in cells from the adult (44). It is conceivable that with maturation, the activity of tryptophan hydroxylase, the rate limiting enzyme in the synthesis of $5 \mathrm{HT}$, is decreased to the extent that the adult cells are unable to make 5HT. Alternatively, because the cells of the fetal neuroendocrine system are more numerous than in the adult intestine, it may represent a transient cell population that disappears with gut maturation. This suggests a possible local neurohormonal control of the development and differentiation of the gut $(43,45)$.

Another possible neural control mechanism that remains to be adequately explored is the peripheral nervous system. Crypt cell division and migration of villous cells in the young postnatal rat occur at a slower rate than in adults $(27,34,37,91)$. In the ileal epithelium the circadian rhythm of crypt cell mitosis is absent at 8 days after birth $(37,39)$ but is present at 15 days of age. The amplitude of the circadian rhythm appears to increase from weaning to adulthood $(37,39)$ and seems to be dependent on sympathetic innervation, since guanethidine-induced sympathectomy causes a significant decrease in the amplitude of the circadian rhythm in both 15-day- and 45-day-old rats $(36,37)$. Chemical sympathectomy before 15 days of age similarly depresses the mitotic and labelling indices (37), presumably by a prolongation of the cell generation cycle as a result of an elongation of both the pre-DNA and the DNA-synthetic period (37). These studies strongly suggest a role of the sympathetic system in controlling the proliferation of intestinal epithelial cells during postnatal development $(35,37,38,90,92)$.

Proximal-distal gradient. One interesting aspect regarding the development of disaccharidases in the small intestine is the establishment of a proximal-distal gradient of enzyme activities. In the human, individual disaccharidase activities appear throughout the intestine in early fetal life. With further development, the enzyme specific activities in the ileum remain constant whereas those in the proximal intestine, notably the first part of the jejunum, continue to increase $(3,4,78)$. The result is the typical topographic distribution of disaccharidases found in the adult; the highest activities in the proximal and mid-jejunum, decreasing more in the orad than in the aborad direction (66).

A number of factors could be contributory to the formation of the gradient, such as the continuity, composition, and texture of the foot stream. The intestinal contents are more acidic and crude 
in the duodenum and more refined, uniform, and slightly alkaline when in the ileum. Indirect evidence suggests that microorganisms may also be modifiers of the development of disaccharidase activity. Germ-free rats have higher disaccharidase activities than rats maintained in a conventional environment $(30,71)$. Further, infection of germ-free rats with cecal content from control rats leads to a reduction of disaccharidase activities (71). Bile and pancreatic secretions are other stimuli of disaccharidase activity. Pancreatic proteases secreted into the intestinal lumen affect disaccharidase turnover $(1,9)$. In pancreatic insufficiency, higher concentrations of disaccharidases can be demonstrated $(6,42)$. Bile stabilizes most pancreatic enzymes and may affect disaccharidase turnover indirectly, but has not been demonstrated to have a direct effect on mucosal enzymes other than by the activation of enteropeptidase $(20,22)$.

In the fetus, there is a relative lack of pancreatic and biliary secretions and an absence of bacteria in the gut during intrauterine life. It is unlikely that bacteria and the presence of pancreatic and/or biliary secretion have a major role in fetal development of the gut. Postnatally, these factors may become important. In fact, luminal content has been shown to have a modulating action on the development and maintenance of some intestinal functions. The proximal distal gradient of fatty acid esterification fails to develop when segments of small intestine are explanted onto the kidney (79). Further in suckling rats, surgically bypassed ileal segment results in immature pattern of high lactase activities with normal pattern of sucrase and maltase for age (89). The findings also suggest the involvement of intraluminal influence in enteric development.

Environmental influences. Genetic endowment provides the potential for development, but full expression requires the presence of an optimal environment. Among the best studied environmental influences of development is the regulation of enzymes during intestinal and pancreatic development by exogenous hormones. Cortisol administration to pregnant rats increased the mucosal enzymes, alkaline phosphatase, and glucosidases of their offspring in a dose-dependent fashion $(29,73)$. Thyroxine has a similar effect of increasing sucrase activities but presumably works indirectly via the stimulation of glucocorticoid secretion by the mother and/or fetus. Glucocorticoid given to 16-day-old rats induces the precocious appearance of sucrase. A similar premature induction of alpha-amylase in the pancreas has also been observed after cortisol administration (76).

Available substrate from the diet is important in modifying the developmental pattern of intestinal and pancreatic enzymes. Intragastric infusion of sucrose to 9-day-old rat pups for 3 days leads to an increase of sucrase and isomaltase but not of lactase (53). Prolonged lactose feeding of rats seems to increase total lactase contents and appears to diminish the postnatal decline (52). In a similar fashion, rat pups fed adult chow have increased pancreatic amylase as compared to litter mates that have no access to the adult chow (81). Because rat milk has a high fat, low carbohydrate content, the relative lack of carbohydrates with prolonged milk feeding may fail to elicit amylase accumulation. Feeding premature infants a high starch diet for 30 days results in the appearance of low level of amylase activities, whereas feeding a high protein diet results in higher trypsinogen and lipase levels in the corresponding pancreatic secretions. Those fed a high fat diet, however, show no change in exocrine pancreatic enzymes (95). Our results from prematures fed milk-based versus soy-based formula show that soy-based formula results in an increase in trypsin and lipase secretion after pancreozymin and secretin stimulation compared to those fed milk-based formula. The soy-based formula appears to promote pancreatic function (49).

An important issue is the environmental influence of pre- and postnatal malnutrition on gastrointestinal development. Intrauterine growth retardation (IUGR) may result from a variety of causes, including toxemia, hypertension, alcoholism, smoking, maternal malnutrition, placental infarction, intrauterine infection, and chromosomal and other inherited disorders. The specific effect of intrauterine growth retardation on the gastrointestinal tract remains to be determined.

Intrauterine growth retardation induced by restricting maternal blood flow to the developing fetal rats during the third trimester leads to a decrease in both intestinal and pancreatic weight due to a reduction in the number of cells $(50,51)$. A significant reduction in total disaccharidase, alkaline phosphatase, and enterokinase is found in the intestinal mucosa, and a reduction in total pancreatic enzymes is also found in affected rat pups $(50,51)$. The specific activities (U/mg protein) of lactase, alkaline phosphatase, pancreatic amylase, and lipase are reduced but maltase, enterokinase, and pancreatic proteases are spared in this model. Newborn rat pups from dams fed low protein diets (6\% of calories) during gestation exhibit a reduction of acinar tissue and content of esterases (by histochemical stain) compared to those from dams fed a normal protein diet $(30 \%)(80)$. A similar decrease in the concentration of exocrine enzymes has also been demonstrated by Klotz et al. (40) in rat pups from dams fed diets containing 5\% casein from the 5th day of gestation to birth, compared to those whose mothers are fed a balanced diet. In organ cultures of fetal pancreas from rats at 13 days of gestation, partial restriction of the methionine concentration permits proliferation but prevents morphologic and biochemical differentiation of the exocrine cells to the adult type (67).

Corresponding results on the effect of intrauterine malnutrition on gastrointestinal development in humans are not available. Extrapolation from animal data suggest that gastrointestinal function in affected neonates may be subnormal when compared to their peers.

Studies of postnatal malnutrition have shown similar observations. Rats undernourished during the suckling period had reduced intestinal and pancreatic weights due to reduction in DNA and cell number $(23,24)$. Pancreatic enzyme contents, expressed per pancreas are diminished; lipase to the greatest extent, trypsin and amylase to an intermediate extent, and chymotrypsin and carboxypeptidase the least. The specific activities of lipase and trypsin are both decreased, lipase being the most severely affected (24). The specific activities of the brush-border enzymes sucrase and maltase are diminished but lactase, enterokinase (23) and leucine aminopeptidase (68) are significantly elevated in the nutritionally deprived pups. Augmentation of D-glucose and glycine uptake, and biochemical changes in the brush-border membranes of the undernourished pups may also be seen (68).

In humans, severe malnutrition in early infancy has been studied to a limited extent. In fatal cases of kwashiorkor, atrophy of the pancreas and intestinal mucosa have been found at autopsy (83). Other studies show that severe malnutrition in young children leads not only to a reduction in zymogen granules in the pancreases, but also to a reduction in the secretory capacity of the pancreatic acini $(5,87)$. Similar studies of intestinal biopsies from marasmic children reveal blunting of villi and elongation of crypts. A corresponding change in ultrastructure, including branching of microvilli and thickening of the basal lateral membrane have also been observed $(7,59)$. Functional derrangement, such as lactose and sucrose intolerance, are also found in a majority of these children $(68,83)$.

These observations may be interpreted as showing apparent retardation of the biological clock as a result of malnutrition. This is especially evident in the concentrations of the intestinal enzymes following postnatal malnutrition, in that the higher lactase and lower maltase, and sucrase levels resemble those of a less mature mucosa (23). The long-term consequences of malnutrition during early development on gastrointestinal physiology are unknown. From the limited data available, it appears that the reduction in exocrine pancreatic function is reversible following dietary correction in most cases $(5,87)$.

Interaction of various determinants. In the previous discussion we have tried to develop the concept that the biological clock determined by the genetic endowment may be modulated by several regulatory mechanisms. Environmental factors can influ- 
ence the expression of the genetic endowment by affecting both the biological clock and regulatory mechanisms, but only at certain stages of development. For example, the cortisol induction of brush-border enzymes in the rat is limited to the fetal and early suckling period, but does not occur after the gut has passed a critical stage of development. Such a concept is very similar to the "critical period hypothesis" as proposed by Moulton in 1923 (65). Restricting agents are considered to have the most detrimental effect when applied during the most rapid period of development. Not only will the ontogenic process be delayed, but the ultimate extent of development may also be limited.

In conclusion, a sound background in developmental physiology and biochemistry provides the pediatrician and pediatric gastroenterologist with a theoretical basis for the nutritional management of premature and compromised infants. The genetic endowment, biological clocks, regulatory mechanisms and environmental influences can enable us to better understand the pathophysiology of selected gastrointestinal diseases. Tissue culture and explants, and other sophisticated analytical methodologies can enhance our insight into the intricate interaction of these determinants. A better definition of the mechanisms controlling the ontogeny of the gut should emerge.

\section{REFERENCES AND NOTES}

1. Alpers, D. H. and Tedesco, F. J.: The possible role of pancreatic proteases in the turn over of intestinal brush border proteins. Biochim. Biophys. Acta, 401: 28 (1975)

2. Anderson, C. M., Messer, M., Townley, R. R., Freeman, M., and Robinson, J $\mathrm{J} .:$ Intestinal isomaltase deficiency in patients with hereditary sucrose and starch intolerance. Lancet, 2: 556 (1962).

3. Antonowicz, I. and Lebenthal, E.: Developmental pattern of small intestina enterokinase and disaccharidase activities in the human fetus. Gastroenterology, 72: 1299 (1977).

4. Auricchio, S., Ciccinarra, F., Vegente, A., Andrea, G., and Vetrella, M.: Enzymatic activity hydrolyzing glutamyl-naphthylamide in human intestine during adult and fetal life. Pediatr. Res., 7: 95 (1973).

5. Barbezat, G. O. and Hansen, J. D. L.: The exocrine pancreas and protein caloric malnutrition. Pediatrics, 42: 77 (1968).

6. Batt, R. M., Bush, B. M., and Peters, T. J.: Biochemical changes in the jejunal mucosa of dogs with naturally occurring exocrine pancreatic insufficiency. Gut, 20: 709 (1979).

7. Brunser, O., Castillo, C., and Araya, M.: Fine structure of the small intestinal mucosal in infantile marasmic malnutrition. Gastroenterology, 70: 495 (1976).

8. Bynum, J. W., Mohrlok, S., and Ronzio, R. A.: RNA synthesis and processing during cytodifferentiation in fetal rat pancreas. Differentiation, 17: 41 (1980).

9. Caspary, W. F., Winckler, K., and Laukisch, P. G.: Influence of exocrine and endocrine pancreatic function in intestinal brush border enzymatic activities. Gut, 16: 89 (1975)

10. Cooper, B. T., Candy, D. C. A., Harries, J. T., and Peters, T. J.: Subcellular fractionation studies of the intestinal mucosa in congenital sucrase-isomaltase deficiency. Clin. Sci., 57: 181 (1979).

11. DeRitis, G., Falchuk, Z. M., and Trier, J. S.: Differentiation and maturation of cultured fetal rat jejunum. Dev. Biol., 45: 304 (1975).

12. Eggermont, E.: The biochemical defects in sucrose intolerance and in glucosegalactose malabsorption. Dissertation, Catholic University of Louvain, (1968).

13. Etzler, M. E. and Branstrator, M. L.: Cell surface components of intestinal epithelial cells and their relationship to cellular differentiation. Ciba Foundation Symposium on Development of Mammalian Absorptive Processes, p. 51 (1979).

14. Euler, A. R., Byrne, W. J., Cousine, L. M., Ament, M. E., Leaks, R. D., and Walsh, J. H.: Increased serum gastrin concentration and gastric acid hyposecretion in the immediate newborn period. Gastroenterology, 72:1271 (1977).

15. Euler, A. R., Byrne, W. J., Meis, P. J., Leaks, R. D., and Ament, M. E.: Basal and pentagastrin stimulated acid secretion in newborn human infants. Pediatr. Res., 13: 36 (1979)

16. Ferguson, A., Gerskowitch, V. P., and Russell, R. I.: Pre- and post-weaning disaccharidase patterns in isografts of fetal mouse intestine. Gastroenterology, 64: 292 (1973).

17. Figarella, C., DeCaro, A., Leupold, D., and Poley, J. R.: Congenital pancreatic lipase deficiency. J. Pediatr., 96: 412 (1980).

18. Gleeson, M. H., Bloom, S. R., Polak, J. M., Henry, K., and Dowling, R. M.: An endocrine turnover in kidney affecting small bowel structure, motility and absorptive function. Gut, 12: 773 (1971).

19. Gray, G. M., Conklin, K. A., and Townley, R. R.: Sucrase-isomaltase deficiency Absence of an inactive enzyme variant. New Engl. J. Med., 295: 750 (1976)

20. Green, G. M. and Nasset, E. S.: Importance of bile in regulation of intraluminal proteolytic enzyme activities in the rat. Gastroenterology, 79: 695 (1980).
21. Grobstein, C.: Cytodifferentiation and its controls. Science, 143: 643 (1964).

22. Hadorn, B., Hess, J., Troesch, V., Verhaage, W., Gotze, H., and Bender, S. W. Role of bile acids in the activation of trypsinogen by enterokinase disturbance of trypsinogen activation in patients with intrahepatic biliary atresia. Gastroenterology, 66: 548 (1974).

23. Hatch, T. F., Lebenthal, E., Branski, D., and Krasner, J.: The effect of early postnatal malnutrition on intestinal growth, disaccharidases and enterokinase. J. Nutr., 109: 1874 (1979).

24. Hatch, T. F., Lebenthal, E., Krasner, J., and Branski, D.: Effect of postnatal malnutrition on pancreatic zymogen enzymes in the rat. Am. J. Clin. Nutr. 32: 1224 (1979).

25. Henning, S.: Plasma concentrations of total and free corticosterone during development in the rat. Am. J. Physiol., 235: 451 (1978).

26. Henning, S., Ballard, P. L., and Kretchmer, N.: A study of the cytoplasmic receptors for glucocorticoids in intestine of pre- and postweaning rats. J. Biol. Chem., 250: 2073 (1975)

27. Herbst, J. J. and Sunshine, P.: Postnatal development of the small intestine of the rat. Changes in mucosal morphology at weaning. Pediatr. Res., 3: 27 (1969).

28. Johnson, L. R.: New aspects of the trophic action of gastrointestinal hormones. Gastroenterology, 72: 788 (1977)

29. Jumawan, J., Celano, P., Horowitz, D., Lau, H., and Koldovsky, O.: Effect of cortisone of $\mathrm{L}$-triiodothyronine administration to pregnant rats on the activity of fetal intestinal disaccharidases and lysosomal acid beta-galactosidase. Biol. Neonate, 32: 211 (1977).

30. Kawai, Y. and Mortomi, M.: Intestinal enzyme activities in germ free, conventional and gnotobiotic rats associated with indigenous microorganisms. Infect. Immun., 9: 771 (1978).

31. Kemp, J. D., Walther, B. T., and Rutter, W. J.: Protein synthesis during the secondary developmental transition of the embryonic rat pancreas. J. Biol. Chem., 247: 3946 (1972)

32. Kendall, K., Jumawan, J., and Koldovsky, O.: Development of jejunoileal differences of activity of lactase, sucrase and beta-galactosidase in isografts of fetal rat intestine. Biol. Neonate, 36: 206 (1979).

33. Kerry, K. R. and Townley, R. R.: Genetic aspects of intestinal sucrase-isomaltase deficiency. Aust. Pediatr. J., 1: 223 (1965).

34. Klein, R. M.: Alteration of cellular proliferation in the ileal epithelium of suckling and weaned rats: the effects of isoproterenol. Cell Tissue Kinet., 10: 353 (1977).

35. Klein, R. M.: Analysis of intestinal cell proliferation after guanethidine-induced sympathectomy. II. Percentage labelled mitosis studies. Cell Tissue Kinet., 12: 649 (1979).

36. Klein, R. M.: Analysis of intestinal cell proliferation after guanethidine-induced sympathectomy. III. Effects of chemical sympathectomy on circadian variation in mitotic activity. Cell Tissue Kinet., 13: 153 (1980).

37. Klein, R. M.: Crypt renewal and chemical sympathectomy in the preclosure ileum of the neonatal rat. Biol. Neonate, 39: 8 (1981)

38. Klein, R. M. and Torres, J.: Analysis of intestinal cell proliferation after guanethidine-induced sympathectomy. I. Stathmokinetic, labelling index, mitotic index, and cellular migration studies. Cell Tissue Res., 195: 239 (1978).

39. Klein, R. M. and Whitney, S. L.: Circadian rhythms in neonatal rat parotid gland acinar cell and ileal crypt cell mitosis. Biol. Neonate, 38: 197 (1980).

40. Klotz, A. P., Murdock, A. L., and Svoboda, D. J.: The effect of protein deterioration on pancreatic function in young animals and in animals in utero. Dig. Dis., 17: 399 (1972).

41. Koldovsky, O.: Development of sucrase activity: Effect of maternal hormonal status and fetal programming of jejuno-ileal differences. Ciba Foundation Symposium on Development of Mammalian Absorptive Processes, p. 147 (1979).

42. Kwong, W. K. L., Seetharam, B., and Alpers, D. H.: Effect of exocrine pancreatic insufficiency on small intestine in the mouse. Gastroenterology, 174: 1277 (1978).

43. Larsson, L. I.: Peptide secretory pathways in GI tract: Cytochemical contributions to regulatory physiology of the gut. Am. J. Physiol., 239: G237 (1980).

44. Larsson, L. I. and Jorgensen, L. M.: Ultrastructural and cytochemical studies on the cytodifferentiation of duodenal endocrine cells. Cell Tissue Res., 194: 79 (1978).

45. Larsson, L. I., Rehfeld, J. F., Sundler, F., and Hankanson, R.: Pancreatic gastrin in fetal and neonatal rats. Nature (London), 262: 609 (1976).

46. Leapman, S. B., Deutsch, A. A., Grand, R. J., and Folkman, J.: Transplantation of fetal intestine: Survival and function in a subcutaneous location in adult animals. Ann. Surg., 179: 109 (1974).

47. Lebenthal, E: Induction of fetal rat enterokinase (enteropeptidase EC 3.4.21.9) in utero by hydrocortisone and actinomycin D. Pediatr. Res., 11: 282 (1977).

48. Lebenthal, E. and Lee, P. C.: Development of functional response in human exocrine pancreas. Pediatrics, 66: 556 (1980)

49. Lebenthal, E. and Lee, P. C. The development of pancreatic function in premature infants after milk based and soy based formulas. Pediatr. Res., 15: $1240(1981)$

50. Lebenthal, E., Nitzan, M., Chrzanowski, B., and Krantz, B.: The effect of reduced maternofetal blood flow on the development of fetal pancreatic acinar cells and zymogens. Pediatr. Res., 14: 1356 (1980)

51. Lebenthal, E., Nitzan, M., Lee, P. C., Chrzanowski, B. L., and Krasner, J.: Small intestinal enzymes during normal development and the effect of intrauterine growth retardation in fetal rats. Biol. Neonate, 39: 14 (1981).

52. Lebenthal, E., Sunshine, P., and Kretchmer, N.: Effect of prolonged nursing on the activity of intestinal lactase in rats. Gastroenterology, 64: 1136 (1973). 
53. Lebenthal, E., Sunshine, P., and Kretchmer, N.: Effect of carbohydrate and corticosteroids on activity of alpha-glucosidases in intestine of the infant rat. J. Clin. Invest., 5I: 1244 (1972).

54. Lebenthal, E., Tsuboi, K., and Kretchmer, N.: Characterization of human intestinal lactase and hetero-beta-galactosidases in infants and adults. Gastroenterology, 67: 1107 (1974).

55. Lowe, C. V. and May, C. D.: Selective pancreatic deficiency. Am. J. Dis. Child., 82: 459 (1951).

56. Lucas, A., Adrian, T. E., Christofides, N., Bloom, S. R., and Aynsley-Green, A.: Plasma motilin, gastrin, and enteroglucagon and feeding in the human newborn. Arch. Dis. Child., 55: 673 (1980).

57. Lucas, A., Bloom, S. R., and Aynsley-Green, A.: Development of hormone responses to feeding in neonates. Arch. Dis. Child., 55: 678 (1980).

58. Malloy, M. H., Morris, F. H., Denson, S. E., Weisbrodt, N. W., Lichtenberger, L. M., and Adcock, E. W.: Neonatal gastric motility in dogs: Maturation and response to pentagastrin. Am. J. Physiol., 236: E562 (1979).

59. Martins Campos, J. V., Fagundes Neto, V., Patricio, F. R. S., Wehba, J., Carvalho, A. A., and Shener, M.: Jejunal mucosa in marasmic children. Clinical, pathological, and prestructural evaluation of the effect of proteinenergy malnutrition and environmental contamination. Am. J. Clin. Nutr., 32: 1575 (1979).

60. Maylic-Pfenninger, M. F. and Jamieson, J. D.: Distribution of cell surface saccharides on pancreatic cells I \& II. J. Cell Biol., 80: 69 (1979).

61. Maylic-Pfenninger, M. P., Doyle, C. M., and Jamieson, J. D.: Differential lectin receptor appearance during the development of the pancreas. J. Cell Biol., 75: 67 a (1977).

62. Meeuwisse, G. and Dahlqvist, A.: Glucose-galactose malabsorption. Lancet, 2 : 858 (1966).

63. Moog, F.: Perinatal development of the enzymes of the brush border membrane In: Emanuel Lebenthal, Ed.: Textbook of Gastroenterology and Nutrition in Infancy, pp. 139-147 (Raven Press, New York, NY, 1981).

64. Morris, M. D. and Fisher, D. A.: Trypsinogen deficiency disease. Am. J. Dis. Child., 114: 203 (1967).

65. Moulton, C. R.: Age and chemical development in mammals. J. Biol. Chem., 57: 79 (1923).

66. Newcomer, A. D. and McGill, D. B.: Distribution of disaccharidase activity in the small bowel of normal and lactase-deficient subject. Gastroenterology, 51: 481 (1966).

67. Parsa, I., Marsh, W. H., and Fitzgerald, P. J.: Pancreas and acinar cell differentiation V. Significance of methyl groups in morphologic and enzymatic development. Exp. Cell Res., 73: 49 (1972).

68. Patlak, R. M., Mahmood, A., Dudeja, P. K., and Subrahmanyam, D.: Intestinal brush border membrane structure and function. Effect of early postnatal undernutrition. Pediatr. Res., 15: 112 (1981).

69. Rall, L. B., Pictet, R. L., Gethens, S., and Rutter, W. J.: Glucocorticoid modulate the in vitro development of the embryonic rat pancreas. J. Cell Biol., 75: 389 (1977).

70. Rausome-Kuti, O., Kretchmer, N., and Johnson, J. D.: A genetic study of lactase digestion in Nigerian families. Gastroenterology, 68: 431 (1975).

71. Reddy, B. S. and Wostmann, B. S.: Intestinal disaccharidase activities in the growing germ free and conventional rats. Arch. Biochem. Biophys., 113: 609 (1966).

72. Rodgers, B. M., Dix, P. M., Talbert, J. L., and MacGuigan, J. E.: Fasting and post prandial serum gastrin in normal human neonates. J. Pediatr. Surg. 13: 13 (1978).

73. Ross, L. and Goldsmith, E. D.: Histochemical studies of effects of cortisone on fetal and newborn rats. Proc. Soc. Exp. Biol. Med., 90: 50 (1955).

74. Rutter, W. J., Kemp, J. D., Bradshaw, W. S., Clark, W. B., Ronzio, R. A., and Sanders, T. G.: Regulation of specific protein synthesis in cytodifferentiation. J. Cell Physiol., 72: Suppl. 1: 1 (1975).
75. Sahi, T., Isokoski, M., Jussila, J., Launiala, K., and Pyorala, K.: Recessive inheritance of adult type lactose malabsorption. Lancet, 2: 823 (1973).

76. Sasaki, A., Mura, M., Takeuchi, T., Furichata, C., Matsushinia, T., and Suginura, T.: Premature induction of amylase in pancreas and parotid gland of growing rat by dexamethasone. Biochim. Biophys. Acta, 428: 619 (1976)

77. Schmitz, J., Bressen, N., Triadou, J., Bataille, J., and Rey, J.: Polyacrylamide gel electrophoresis of brush border membrane proteins and of cytoplasmic protein in 8 cases of congenital sucrose intolerance. Gastroenterol. Clin. Biol., 4: 251 (1980).

78. Sheehy, T. W. and Anderson, P. R.: Fetal disaccharidases. Am. J. Dis. Child., 121: 464 (1971).

79. Shiau, Y. F., Umstetter, C., Kendall, K., and Koldovsky, O.: Development of fatty acid esterification mechanisms in rat small intestine. Am. J. Physiol., 237: E399 (1979)

80. Shrader, R. E. and Zeman, F. J.: Effect of maternal protein deterioration on morphological and enzymatic development of neonatal rat tissue. J. Nutr. 99: 401 (1970).

81. Snook, J. T.: Effect of diet on development of exocrine pancreas of the neonatal rat. Am. J. Physiol., 221: 1388 (1971).

82. Spooner, B. S., Cohen, H. I., and Faubion, J.: Development of the embryonic mammalian pancreas: The relationship between morphogenesis and cytodifferentiation. Dev. Biol., 61: 119 (1977).

83. Stransky, E. and David-Laws, D. F.: On Kwashiorkor (Infantile pellagra, malignant malnutrition). Ann. Pediatr., 174: 226 (1950)

84. Takeuchi, K., Peitsch, W., and Johnson, L. R.: Mucosal gastrin receptor. V. Development in newborn rats. Am. J. Physiol., 3: G163 (1981).

85. Takeuchi, K., Speir, G. R., and Johnson, L. R.: Mucosal gastrin receptor. Regulation by gastrin. Am. J. Physiol. (Gastrointest. Liver Physiol. 1), 238: G135 (1980).

86. Tata, J. R.: Modulation of hormone receptors. Nature (London), 269: 757 (1977).

87. Thompson, M. D. and Trowell, H. C.: Pancreatic enzyme activity in duodenal contents of children with a type of kwashiorkor. Lancet, 1 : 1031 (1951).

88. Townes, P. L.: Trypsinogen deficiency disease. J. Pediatr., 66: 275 (1965).

89. Tsuboi, K. K., Kwong, L. K., Andrew, W. D., Ford, T. C., and Sunshine, P.: Delayed ontogenic development in the bypassed ileum of the infant rat. Gastroenterology, 80: 1550 (1981).

90. Tutton, P. J. M.: Neural stimulation of mitotic activity in the crypts of Lieberkuhn in rat jejunum. Cell Tissue Kinet., 8: 259 (1975).

91. Tutton, P. J. M.: Variations in crypt cell cycle time and mitotic time in the small intestine of the rat. Virchows Arch. Abt. B. Zellpath., 13: 68 (1973).

92. Tutton, P. J. M. and Helme, R. D.: The influence of adrenoreceptor activity on crypt cell proliferation in the rat jejunum. Cell Tissue Kinet., 7: 125 (1974).

93. Van Nest, G. A., MacKonald, R. J., Raman, R. K., and Rutter, W. J.: Protein synthesized and secreted during rat pancreatic development. J. Cell Biol., 86: 784 (1980).

94. Zimmermann, E. G.: Peptides of the brain and gut. Introductory remarks. Fed. Proc., 38: 2286 (1979).

95. Zoppi, G., Andreotti, G., Pajno-Ferrara, F., Njai, D. M., and Gaburro, D.: Exocrine pancreas function in premature and full term neonates. Pediatr. Res., 6: 880 (1972).

96. The authors thank Drs. Robin Bannerman, Leo Heitlinger, Edwin Naylor, Erwin Neter, Mary Voorhess, and Milton Weiser for their helpful suggestions in the preparation of the manuscript.

97. Requests for reprints should be addressed to: Dr. Emanuel Lebenthal, Professor of Pediatrics, Chief, Division of Gastroenterology and Nutrition, Children's Hospital of Buffalo, 219 Bryant Street, Buffalo, New York 14222.

98. Received for publication December 22, 1981

99. Accepted for publication April 23, 1982.

100. This work was supported in part by grants NIH \#12586 and NSF \#21817. 